\title{
Importance of intestinal colonisation in the maturation of humoral immunity in early infancy: a prospective follow up study of healthy infants aged $0-6$ months
}

\author{
M-M Grönlund, H Arvilommi, P Kero, O-P Lehtonen, E Isolauri
}

\begin{abstract}
Aim-To evaluate the role of intestinal microflora and early formula feeding in the maturation of humoral immunity in healthy newborn infants.

Study design-Sixty four healthy infants were studied. Faecal colonisation with Bacteroides fragilis group, Bifidobacterium-like, and Lactobacilluslike bacteria was examined at 1, 2, and 6 months of age, and also the number of IgA-secreting, IgM-secreting, and IgGsecreting cells (detected by ELISPOT) at 0,2 , and 6 months of age.

Results-Intestinal colonisation with bacteria from the $B$ fragilis group was more closely associated with maturation of IgAsecreting and IgM-secreting cells than colonisation with the other bacterial genera studied or diet. Infants colonised with $B$ fragilis at 1 month of age had more IgAsecreting and IgM-secreting cells $/ 10^{6}$ mononuclear cells at 2 months of age (geometric mean (95\% confidence interval) 1393 (962 to 2018) and 754 (427 to 1332) respectively) than infants not colonised (1015 (826 to 1247) and 394 (304 to 511) respectively); $p=0.04$ and $p=0.009$ respectively.
\end{abstract}

Conclusions-The type of bacteria colonising the intestine of newborns and the timing may determine the immunomodulation of the naive immune system.

(Arch Dis Child Fetal Neonatal Ed 2000;83:F186-F192)

Department of Paediatrics, Turku University Central Hospital, Turku,

Finland

M-M Grönlund

P Kero

E Isolauri

Clinical Microbiology, Turku University Central Hospital $M-M$ Grönlund

O-P Lehtonen

National Public Health Institute, Turku,

Finland

H Arvilommi

Correspondence to:

Dr Grönlund, Department of

Paediatrics, Turku University

Central Hospital, Box 52,

FI-20521 Turku, Finland

minna-maija.gronlund@utu.fi

Accepted 12 May 2000
Keywords: intestinal colonisation; immune system; immunoglobulin secreting cell; ELISPOT; humoral immunity; delivery method

From the first moments after birth, the gastrointestinal tract is constantly challenged by a myriad of bacterial and food antigens. More than $70 \%$ of all immune cells in the human body are located in the intestine to combat this challenge. ${ }^{1}$ Therefore there is important immunological protection in the milieu where most new antigens are encountered. ${ }^{2}$ This immunological protection, primarily composed of locally produced secretory $\operatorname{IgA}$, is quantitatively and functionally defective for a variable period after birth. ${ }^{3}$ The number of IgA plasma cells in the duodenal mucosa reaches that of adults by 2 years of age, whereas the level of mucosal secretory IgA antibodies reaches adult levels only at the age of 6-8 years. ${ }^{4}$ It has been postulated that undevel- oped mucosal immunological protection is the reason for the higher vulnerability to infection and the more prevalent sensitisation to dietary antigens seen in early infancy. ${ }^{3}$

Considering that the mucosal surfaces harbour more bacterial cells than the total number of cells found in the human body, surprisingly little is known about the role of early bacterial colonisation in the development of the immune system in man. The involvement of intestinal colonisation in the fine tuning and maturation of immune responses is well characterised in animal models: both the gut associated immune system and systemic immunity mature on stimulation by the intestinal microflora. ${ }^{16-8}$ Furthermore, the timing of the intestinal microbial stimulus seems to be important: neonatal germ-free mice can be made tolerant to food antigens only if the intestinal flora is in place during the neonatal period, whereas later reconstitution fails to allow oral tolerance to be induced. ${ }^{9}$ Studies in humans have focused only on the effects of intestinal colonisation on specific humoral immunity against the colonising bacteria, ${ }^{10-12}$ and no data exist on the relation between early intestinal colonisation and maturation of spontaneous overall humoral immunity.

Although the interrelationship between environmental determinants and development of the immune system in humans remains obscure, an increasing number of newborns are exposed to factors that delay intestinal colonisation. These factors include premature birth, delivery by caesarean section, and treatment with antimicrobials. ${ }^{13-16}$ These factors, along with the "over-hygienic" nature of western society, may deprive infants of an important antigenic stimulus offered by the intestinal flora. ${ }^{17}$

In an attempt to understand the association between microbial colonisation of the intestine and development of non-specific humoral immunity in man, we studied the faecal flora and number of IgA-secreting, IgG-secreting, and IgM-secreting cells in 64 healthy infants.

\section{Methods}

SUBJECTS AND STUDY DESIGN

The study group consisted of 64 healthy full term newborns of healthy mothers delivered at the Department of Obstetrics and Gynecology, University Central Hospital, Turku, Finland. Infants were enrolled after written informed consent had been obtained from their parents. Thirty four infants were delivered vaginally and 
30 by elective caesarean section because of disproportion or malpresentation. The mothers delivering by caesarean section received $2 \mathrm{~g}$ ampicillin intravenously two hours before delivery for selective intrapartum chemoprophylaxis. None of the mothers had received antimicrobial agents in the month before delivery. After delivery, the newborns were admitted randomly to one of the two maternity wards for healthy newborn infants. The study was approved by the joint commission on ethics of Turku University and Turku University Central Hospital.

The mothers kept a diary for the first two months of the infant's life on nutrient intake (breast feeding/quality and volume of formula feeding), any antimicrobial treatment, frequency of normal/colicky crying, ${ }^{18}$ and the quality and number of stools and vomiting. Further information on feeding, health, growth, and antimicrobial treatment between the ages of 2 and 6 months was collected at a scheduled visit at 6 months of age. The children were clinically examined at the ages of 2 and 6 months, always by the same investigator (MMG). Eleven of the study infants received antimicrobial treatment for upper respiratory tract infection between the ages of 2 and 6 months. These infants were excluded from the study at 6 months of age.

FAECAL CULTURES

Detailed data on the bacterial culture methods used are presented elsewhere. ${ }^{19}$ Briefly, faecal bacteria were examined at the ages of 3-5 days, 10 days, and 1,2 , and 6 months by plating on several selective and non-selective culture media. Quantitative counts were obtained for the following bacterial groups: total, aerobic enteric, Bifidobacterium-like, Bacteroides fragilis group ( $B$ fragilis), Clostridium perfringens, and Lactobacillus-like. Bacterial counts were expressed as $\log _{10}$ colony-forming units (CFUs) per $\mathrm{g}$ wet weight of faeces. Faecal colonisation for a particular bacterial group was considered positive if the bacteria could be detected in the faeces.

IMMUNOGLOBULIN-SECRETING CELLS (ISCS) An umbilical cord blood sample (mixed blood) and peripheral venous blood samples at the ages of 2 and 6 months were collected for analysis. A 1-5 ml sample of blood was taken into a $5 \mathrm{ml}$ EDTA tube. The numbers of circulating antigen-non-specific IgA-secreting, IgGsecreting, and IgM-secreting cells (ISCs) were measured by the enzyme linked immunospot method (ELISPOT), an enzyme linked immunosorbent assay (ELISA) plaque method, ${ }^{20}{ }^{21}$ as described previously. ${ }^{22}$ The total number of IgA-secreting, IgG-secreting, and IgM-secreting cells was calculated to assess the total number of ISCs.

EFFECT OF INTESTINAL MICROFLORA AND TYPE OF FEEDING ON THE NUMBER OF ISCS

The faecal colonisation results for $B$ fragilis, Bifidobacterium-like, and Lactobacillus-like bacteria at 1 and 2 months of age were used in this study to divide the infants into colonised and non-colonised subgroups. We chose to compare the faecal colonisation results at 1 month of age (colonised/non-colonised) with the number of ISCs at 2 months of age, and the colonisation results at 2 months of age with the number of ISCs at 6 months of age. This was because it has been shown that mucosal immunity reaches its highest level four to six weeks after artificial colonisation with Escherichia coli in newborn infants ${ }^{12}$ and that prolonged exposure to antigens in the intestine induces a prolonged response of ISCs. ${ }^{23}$ Furthermore, the diet at this age is composed mostly of milk, ${ }^{24}$ and the association between diet and ISCs could thus be detected by comparing the form of milk received by the infants. Infants were divided into two feeding groups according to their diet at 2 months of age: exclusively breast fed and partly or totally formula fed.

Secondly, to investigate whether the duration of colonisation is important for the development of ISCs, the colonisation time for $B$ fragilis was used to divide the infants into four different colonisation groups (colonised before 1 month of age, colonised at 1-2 months of age, colonised at 2-6 months of age, and not colonised during the study period). The number of ISCs at 2 and 6 months of age was then compared among these four colonisation groups. Some infants had fluctuating $B$ fragilis colonisation during the study period-for example, positive at 1 month, negative at 2 months, positive at 6 months; or negative at 1 month, positive at 2 months, negative at 6 months; or positive at 1 month and 2 months, negative at 6 months; or positive at 1 month and negative at 2 and 6 months. The results for these infants were omitted from the analysis.

\section{STATISTICAL ANALYSIS}

The Mann-Whitney U test was used to test the difference in bacterial counts, and Fisher's exact test to test the difference in bacterial colonisation rates between the feeding groups. Friedman's test was used to analyse the time effect on ISCs, and Wilcoxon signed rank sum test to test the differences between specific time periods. To analyse simultaneously the effect of bacterial colonisation and diet on the number of ISCs, two way analysis of variance was used after logarithmic $\left(\log _{10}\right)$ transformation of the ISC data. When the number of ISCs was compared between the groups of infants colonised with $B$ fragilis at different time points, one way analysis of variance was used after logarithmic transformation of the ISC data. Spearman's rank correlation coefficient was used to correlate faecal bacterial counts with the number of ISCs. Bacterial counts are expressed as the median with range or interquartile range (IQR), and ISC results as the geometric mean with $95 \%$ confidence intervals (95\% CI).

\section{Results}

CLINICAL DATA OF STUDY INFANTS

The mean gestational age of the study infants was 39 weeks (range 37-42), the mean birth weight was $3575 \mathrm{~g}$ (range 2640-4480), and the median Apgar scores at 1, 5, and 15 minutes were $9(3-10), 9(7-10)$, and $9(8-10)$. The 
Table 1 Median and range of faecal bacterial counts (CFUs/g wet weight of faeces) of colonised infants and the colonisation rates at 3, 10, 30, 60, and 180 days of age

\begin{tabular}{|c|c|c|c|c|c|}
\hline & 3 days & 10 days & 30 days & 60 days & 180 days \\
\hline \multicolumn{6}{|l|}{ Total bacteria } \\
\hline Median & 10.6 & 11.1 & 11.1 & 11.2 & 11.2 \\
\hline Range & $7.0-11.9$ & $9.3-12.1$ & $10.2-11.9$ & $10.1-13.7$ & $9.9-13.5$ \\
\hline Colonisation rate & $64 / 64(100)$ & $59 / 59(100)$ & $62 / 62(100)$ & $62 / 62(100)$ & $51 / 51(100)$ \\
\hline \multicolumn{6}{|c|}{ Aerobic enteric bacteria } \\
\hline Median & 9.7 & 9.7 & 9.7 & 9.7 & 9.5 \\
\hline Range & $6.6-10.9$ & $8.1-12.0$ & $7.2-11.0$ & $6.6-13.1$ & $7.5-11.7$ \\
\hline Colonisation rate & $63 / 64(98)$ & $57 / 57(100)$ & $62 / 62(100)$ & $62 / 62(100)$ & $51 / 51(100)$ \\
\hline \multicolumn{6}{|c|}{ Bacteroides fragilis group bacteria } \\
\hline Median & 8.7 & 9.3 & 9.4 & 9.3 & 9.5 \\
\hline Range & $4.8-10.2$ & $4.0-10.4$ & $5.5-10.6$ & $5.5-11.1$ & $5.5-12.3$ \\
\hline Colonisation rate & $23 / 63(37)$ & $16 / 58(28)$ & $21 / 60(35)$ & $30 / 62(48)$ & $30 / 51(59)$ \\
\hline \multicolumn{6}{|c|}{ Lactobacillus-like bacteria } \\
\hline Median & 7.8 & 8.8 & 9.3 & 9.0 & 9.2 \\
\hline Range & $6.4-10.2$ & $6.5-10.5$ & $6.6-10.3$ & $5.7-10.9$ & $5.8-10.1$ \\
\hline Colonisation rate & $7 / 64(11)$ & $14 / 58(24)$ & $21 / 62(47)$ & $29 / 62(47)$ & $23 / 51(45)$ \\
\hline \multicolumn{6}{|c|}{ Bifidobacterium-like bacteria } \\
\hline Median & 10.1 & 10.7 & 10.8 & 10.9 & 10.9 \\
\hline Range & $5.1-11.1$ & $5.1-11.8$ & $6.4-11.6$ & $7.2-11.8$ & $8.9-12.1$ \\
\hline Colonisation rate & $39 / 63(62)$ & $45 / 58(78)$ & $54 / 60(90)$ & $55 / 61(90)$ & $47 / 49(96)$ \\
\hline \multicolumn{6}{|l|}{ Clostridium perfringens } \\
\hline Median & 7.3 & 6.9 & 8.1 & 6.9 & 6.7 \\
\hline Range & $3.8-8.7$ & $4.1-9.1$ & $4.5-9.5$ & $5.8-10.0$ & $5.5-9.0$ \\
\hline Colonisation rate & $7 / 64(11)$ & $11 / 58(19)$ & $21 / 57(37)$ & $14 / 56(25)$ & $11 / 49(22)$ \\
\hline
\end{tabular}

Values in parentheses are percentages.

number of exclusively breast fed infants at 2 months of age was $41(64 \%), 15$ infants were partially formula fed (23\%) and six exclusively formula fed (9\%), and in two cases (3\%) information on the type of feeding was missing.

ESTABLISHMENT OF FAECAL MICROFLORA

Table 1 shows the colonisation rates (\%) and counts (CFUs/g wet weight of faeces) of bacteria studied (total, aerobic enteric, $B$ fragilis, Bifidobacterium-like, Lactobacillus-like bacteria, and $\mathrm{Cl}$ perfringens).

The type of feeding was shown to affect the counts of $B$ fragilis and the colonisation rate of Lactobacillus-like bacteria. Infants who received formula feeds before 2 months of age had higher median counts of $B$ fragilis at 1 and 6 months of age than those exclusively breast fed over 2 months. The median (IQR) counts of $B$ fragilis at 1 month of age were $10.3(9.4-10.4)$ CFUs/g in formula fed infants and 9.0 (8.5-9.6) CFUs/g in breast fed infants $(\mathrm{p}=0.02)$, and at 6 months of age 10.4 (9.3-11.0) and 9.0 (8.0-9.5) CFUs/g respectively $(p=0.01)$. In addition, a higher proportion of formula fed infants were colonised with Lactobacillus-like bacteria at 3 days of age than exclusively breast fed infants $(72 \% v 44 \%$ respectively; $p=0.04$ ) and tended to have a higher colonisation rate at 10 days of age $(85 \%$ $v 57 \%$ respectively; $\mathrm{p}=0.05$ ).

ONTOGENY OF ISCS

Most of the study infants already had detectable IgG-secreting and IgM-secreting cells in the cord blood, whereas only a few had detectable IgA-secreting cells. The number of ISCs increased significantly with age $(\mathrm{p}<0.001)$ (fig 1A-D). A major increase in all immunoglobulin isotypes had occurred by the age of 2 months $(p<0.001)$, and a further rise was observed between the ages of 2 and 6 months in the IgG isotype ( $p<0.001)$ (fig $1 \mathrm{~B})$, but less profoundly in the IgA ( $\mathrm{p}=0.07)$ and IgM isotypes $(\mathrm{p}=0.14)($ fig $1 \mathrm{~A}, \mathrm{C})$.
ASSOCIATION BETWEEN INTESTINAL ANTIGEN STIMULATION AND THE NUMBER OF ISCS Intestinal antigen stimulation at 1 month of age $v$ number of ISCs at 2 months of age

Colonisation with bacteria of the $B$ fragilis group was most clearly associated with the development of ISCs, compared with the other bacteria studied or the effect of diet. Infants colonised with $B$ fragilis at 1 month of age had more ISCs at 2 months of age than noncolonised infants (fig 2). Two way analysis of variance showed this association to be statistically significant. Infants colonised with $B$ fragilis had more IgA-secreting cells than noncolonised infants $(p=0.04)$ (table 2$)$. Further, early formula feeding (before 2 months of age) also tended to increase the number of IgAsecreting cells at 2 months of age $(\mathrm{p}=0.06)$ (table 2). Both colonisation with $B$ fragilis and early formula feeding increased, in a parallel way, the number of IgM-secreting cells $(p=0.009$ for bacterial colonisation and $\mathrm{p}=0.05$ for formula feeding) and the total number of ISCs ( $p=0.01$ for bacterial colonisation and $p=0.02$ for formula feeding) at 2 months of age (table 2). The number of IgG-secreting cells was not associated with $B$ fragilis colonisation at 1 month of age or with early formula feeding $(\mathrm{p}=0.12$ and $\mathrm{p}=0.15$ respectively) (table 2).

Colonisation with Lactobacillus-like bacteria and Bifidobacterium-like bacteria at 1 month of age was not associated with the number of ISCs at 2 months of age (data not shown).

\section{Intestinal antigen stimulation at 2 months of age} $v$ number of ISCs at 6 months of age

A further association was found between $B$ fragilis colonisation at 2 months of age and the number of IgM-secreting cells at 6 months of age. Infants colonised with $B$ fragilis at 2 months of age tended to have more IgMsecreting cells at 6 months of age than non-colonised infants (geometric mean (95\% CI) 1029 (691 to 1533 ) and 622 (447 to 868 ) 

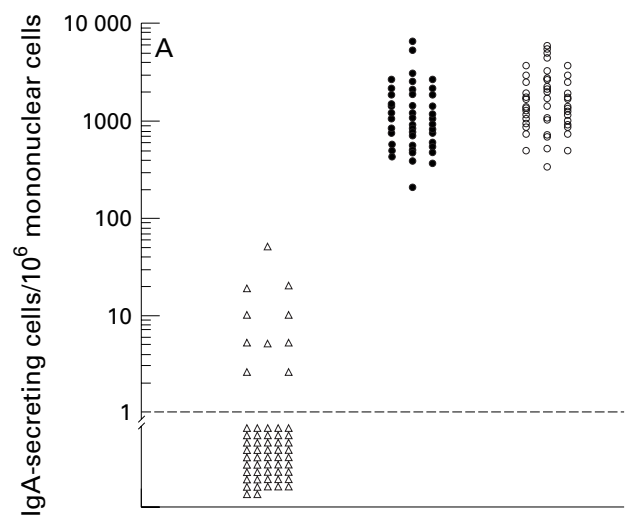

Age (months)... Number of infants... 57 0
57 59

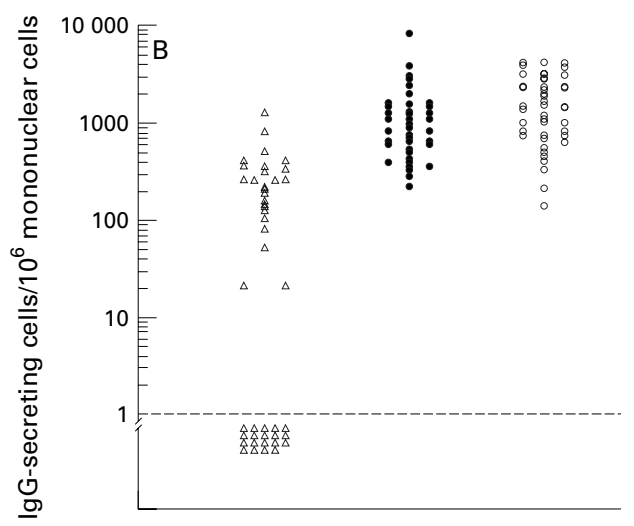

Age (months)... Number of infants... 44

6 50

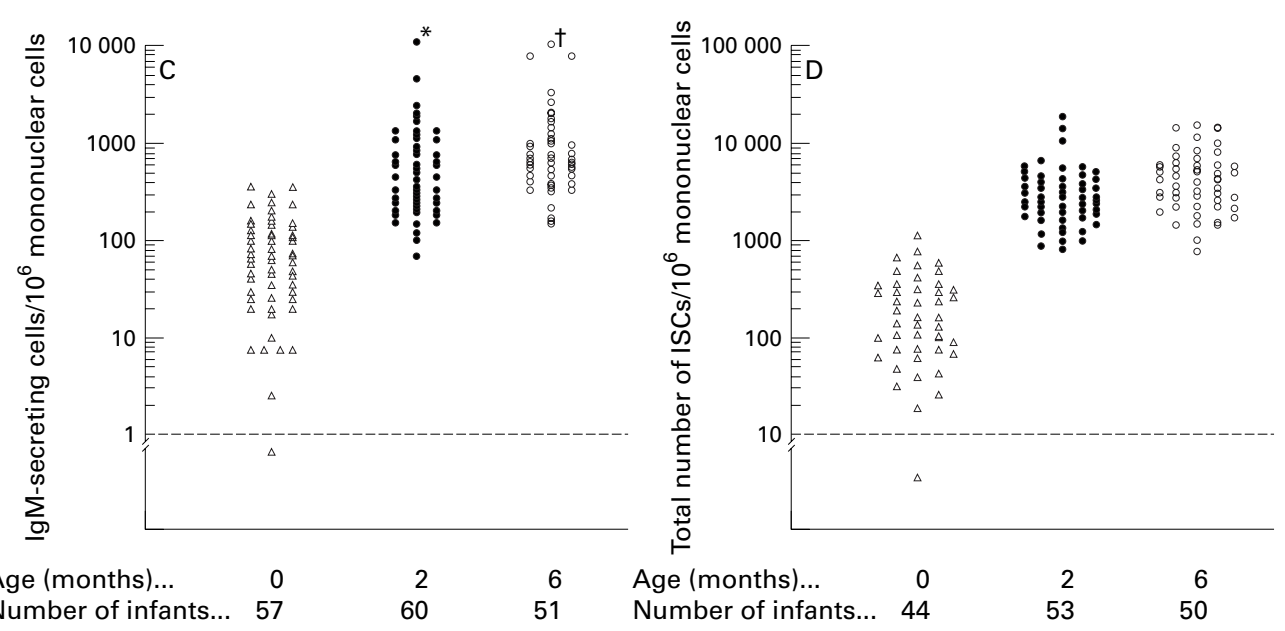

Figure 1 Development of (A) IgA-secreting cells, (B) IgG-secreting cells, (C) IgM-secreting cells, and (D) total number of immunoglobulin-secreting cells (ISCs) in healthy infants aged 0, 2, and 6 months. The frequency of each isotype increased significantly with age $(p<0.001)(A-C)$. A major increase in all isotypes had occurred by the age of 2 months $(p<0.001)$, and a further rise was observed between the ages of 2 and 6 months in the IgG isotype $(p<0.001)(B)$, but less profoundly in IgA $(p=0.07)$ or IgM $(p=0.14)$ ( $A$ and $C)$. Each symbol represents one infant. ${ }^{\star} 11200$ IgM-secreting cells/10 mononuclear cells; +10400 IgM-secreting cells/10 mononuclear cells.

IgM-secreting cells $/ 10^{6}$ mononuclear cells respectively; $\mathrm{p}=0.06)$. Early formula feeding was not further associated with the number of IgM-secreting cells at 6 months of age $(\mathrm{p}=0.83)$.

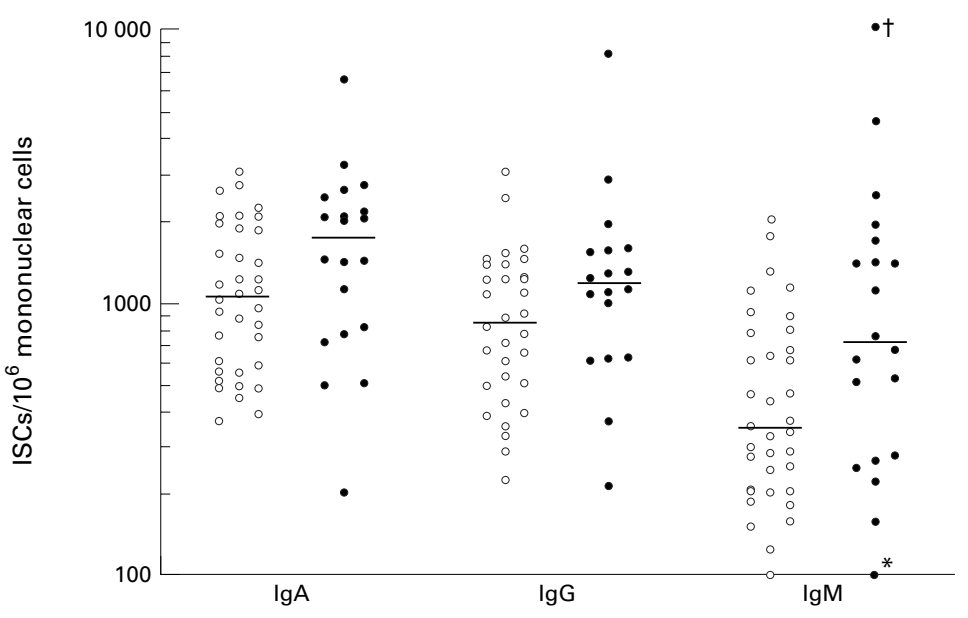

Figure 2 Number of IgA-secreting, IgG-secreting, and IgM-secreting cells at 2 months of age in healthy infants who were either not colonised (O) or colonised ( $\bullet$ with $B$ fragilis at 1 month of age. Each symbol represents one infant and the bar denotes the geometric mean. *70 IgM-secreting cells $/ 10^{6}$ mononuclear cells; +11 200 IgM-secreting cells $/ 10^{6}$ mononuclear cells.
There was no association between colonisation by Lactobacillus-like and Bifidobacteriumlike bacteria at 2 months of age and the number of ISCs at 6 months of age.

Correlation between number of intestinal bacteria and number of ISCs

A positive correlation was observed between the faecal counts of $B$ fragilis and Bifidobacterium-like bacteria and the number of ISCs: the higher the faecal count of $B$ fragilis at 1 month of age, the higher the number of IgAsecreting and IgM-secreting cells at 2 months of age $(\rho=0.27, p=0.05$ and $\rho=0.29$, $\mathrm{p}=0.03$ respectively). In addition, the faecal count of Bifidobacterium-like bacteria at 1 month of age and the number of IgM-secreting cells at 2 months of age correlated positively $(\rho=0.36, p=0.006)$, whereas the faecal counts of Lactobacillus-like bacteria did not correlate with the number of ISCs at any time point.

Association between the time of colonisation and the number of ISCs

In order to study whether the duration of colonisation is important for the development of ISCs, the timing of $B$ fragilis colonisation was 
Table 2 Effect of intestinal colonisation with Bacteroides fragilis group bacteria at 1 month of age, and type of feeding on the number of IgA-secreting, IgG-secreting, and IgM-secreting cells and the total number of immunoglobulin-secreting cells (ISCs) in peripheral blood at 2 months of age in healthy infants

\begin{tabular}{|c|c|c|c|c|}
\hline & \multicolumn{2}{|l|}{ Colonised } & \multicolumn{2}{|l|}{ Non-colonised } \\
\hline & Formula fed ( $n=7)$ & Breast fed $(n=12)$ & Formula fed $(n=14)$ & Breast fed $(n=22)$ \\
\hline \multicolumn{5}{|l|}{ Isotype of ISC } \\
\hline $\operatorname{IgA}^{\star}$ & 2238 (1334 to 3754$)$ & 1057 (624 to 1789$)$ & 1013 (659 to 1558$)$ & 1016 (806 to 1280$)$ \\
\hline $\mathrm{IgG} \dagger$ & $1400(435$ to 4495$)$ & 928 (628 to 1372$)$ & 908 (592 to 1394$)$ & $727(550$ to 961$)$ \\
\hline IgM & 1352 (372 to 4915$)$ & $520(266$ to 1014$)$ & 425 (276 to 655$)$ & $376(264$ to 534$)$ \\
\hline Total number of ISCs $₫$ & 5911 (2233 to 15644$)$ & $2628(1832$ to 3770$)$ & 2503 (1664 to 3767 ) & 2281 (1841 to 2826$)$ \\
\hline
\end{tabular}

Data are given as geometric mean with $95 \%$ confidence interval of ISCs $/ 10^{6}$ mononuclear cells.

*Two way analysis of variance: $\mathrm{p}=0.04$ for colonisation and $\mathrm{p}=0.06$ for type of feeding; interaction $\mathrm{p}=0.06$.

†Two way analysis of variance: $\mathrm{p}=0.12$ for colonisation and $\mathrm{p}=0.15$ for type of feeding; interaction $\mathrm{p}=0.66$.

$¥$ Two way analysis of variance: $\mathrm{p}=0.009$ for colonisation and $\mathrm{p}=0.05$ for type of feeding; interaction $\mathrm{p}=0.13$.

$\S$ Two way analysis of variance: $\mathrm{p}=0.01$ for colonisation and $\mathrm{p}=0.02$ for type of feeding; interaction $\mathrm{p}=0.06$.

used to divide the infants into four groups: colonised before 1 month of age, colonised at 1-2 months of age, colonised at 2-6 months of age, and not colonised during the study period.

The number of $\operatorname{IgA}$-secreting cells at 2 months of age and IgM-secreting cells at 6 months of age differed between the colonisation groups (table 3 ). In both cases, the highest numbers of ISCs were found in infants colonised at 1-2 months of age and the lowest numbers in those not colonised. In the case of IgA-secreting cells at 2 months of age, the second highest counts were found in infants colonised at 1 month of age, and for IgM-secreting cells at 6 months of age, in infants colonised at 2-6 months of age. Even though the numbers of IgM-secreting cells at 2 months of age and IgA-secreting cells at 6 months of age did not differ statistically between the colonisation groups, the kinetics of colonisation were very similar for both of these immunoglobulin classes to those for IgA-secreting cells at 2 months and IgM-secreting cells at 6 months of age (table 3). No effect of the timing of colonisation with $B$ fragilis could be found on the number of IgG-secreting cells at 2 and 6 months of age (data not shown).

\section{Discussion}

The role of early exposure to food antigens in the immunomodulation of the naive immune system has been extensively investigated. Whether this exposure leads to sensitisation or development of oral tolerance remains elusive. $^{325-27}$ What has not been established is the involvement of the massive bacterial antigenic challenge by normal intestinal flora in the maturation of overall humoral immunity in humans. ${ }^{3} 17$
In an attempt to clarify this, we studied faecal colonisation by $B$ fragilis and Bifidobacterium-like and Lactobacillus-like bacteria using classic bacterial culture methods, and compared the colonisation results with the number of ISCs in the peripheral blood, measured by the ELISPOT method in infants aged 2-6 months. It is clear that intestinal microflora is an extremely complex microenvironment to study. ${ }^{28}$ Therefore, to investigate host-microbe interactions in man, we chose indicators of the predominant species of intestinal microflora in infants ${ }^{29} 30$.

Intestinal colonisation with $B$ fragilis was associated with elevated numbers of IgAsecreting and IgM-secreting cells in the peripheral blood. This association was consistent at different ages and more clearly observed than that of the other bacterial genera studied or early formula feeding. To our knowledge, this is the first report of an association between Bacteroides sp and maturation of humoral immunity in humans, and it provides a fresh view of the role of these predominant bacteria of the human gut. To date, most research in this field has concentrated on the immunostimulating properties of lactic acid bacteria, ${ }^{31}$ and Bacteroides sp have been regarded mainly as opportunistic pathogens. ${ }^{32}$

Our results agree with experimental studies showing that bacteria of the genus Bacteroides have stronger immunogenic potential for IgA plasma cells of the duodenal lamina propria than several other strains of intestinal microflora, ${ }^{33}$ and they liberate low molecular mass peptides with immunotriggering activity. ${ }^{34}$ Our results indicate that these observations may also apply to the Bacteroides sp bacteria of the intestinal microflora in humans.

Table 3 Effect of colonisation time with Bacteroides fragilis group bacteria on the number of IgA-secreting and IgM-secreting cells in peripheral blood at 2 and 6 months of age

\begin{tabular}{|c|c|c|c|c|c|}
\hline & \multicolumn{4}{|l|}{$B$ fragilis colonisation } & \multirow[b]{2}{*}{$p$ Value $^{\star}$} \\
\hline & $\begin{array}{l}\text { Before } 1 \text { month of age } \\
(n=15)\end{array}$ & $\begin{array}{l}\text { At } 1-2 \text { months of age } \\
(n=5)\end{array}$ & $\begin{array}{l}\text { At } 2-6 \text { months of age } \\
(n=7)\end{array}$ & $\begin{array}{l}\text { Never during the } \\
\text { study period }(n=13)\end{array}$ & \\
\hline \multicolumn{6}{|c|}{ Number of ISCs at 2 months } \\
\hline IgA & $1410(953$ to 2087$)$ & 1809 (1029 to 3180$)$ & 1289 (710 to 2340$)$ & $814(602$ to 1100$)$ & 0.048 \\
\hline $\operatorname{IgM}$ & 631 (303 to 1319$)$ & 781 (324 to 1883$)$ & $505(310$ to 823$)$ & $360(221$ to 587$)$ & 0.39 \\
\hline \multicolumn{6}{|c|}{ Number of ISCs at 6 months } \\
\hline $\operatorname{IgA}$ & $1511(1186$ to 1925$)$ & $2429(979$ to 6023$)$ & 1249 (723 to 2158$)$ & $1286(799$ to 2071$)$ & 0.26 \\
\hline IgM & $788(470$ to 1321$)$ & 2288 (436 to 12001$)$ & 885 (488 to 1603$)$ & 461 (307 to 692$)$ & 0.012 \\
\hline
\end{tabular}

Data are given as geometric mean with $95 \%$ confidence interval of immunoglobulin-secreting cells (ISCs) $/ 10^{6}$ mononuclear cells. *Analysis of variance; overall difference between groups of infants colonised at different time points. 
Further, our results are consistent with observations from murine studies showing that bacteria of the normal flora induce the immune system much more effectively than food antigens. ${ }^{35}$

Experimental studies have shown that maternal breast milk IgA can forestall the production of natural IgA in gut associated lymphoid tissue of the offspring. ${ }^{36}$ This could explain the lower number of ISCs in the breast fed infants compared with the formula fed infants in our study. The type of feeding may influence maturation of the immune system on two levels. Firstly, breast milk affects the colonisation process of young infants; in the present study breast fed infants had lower faecal counts of $B$ fragilis at 1 and 6 months of age than formula fed infants. Secondly, a trend towards positive interaction between type of feeding and $B$ fragilis colonisation was shown in the number of IgA-secreting cells and the total number of ISCs when analysed by two way analysis of variance (table 2). This indicates that the association between intestinal $B$ fragilis colonisation and the number of ISCs is more prominent if the duration of breast feeding is short, which further agrees with the experimental data showing that maternal IgA prevents stimulation of the mucosal immune system. ${ }^{36}$

The timing of colonisation with $B$ fragilis was further shown to be important for the development of IgA-secreting and IgM-secreting cells. The highest number of IgA-secreting cells at 2 months of age and IgM-secreting cells at 6 months of age were found in infants colonised at 1-2 months of age, and the lowest number of ISCs was found in infants who were never colonised during the six month follow up period. This agrees with the work on mice, implying that the timing of the intestinal microbial stimulus is of utmost importance for the development of the mucosal immune system. ${ }^{9}$

The predominance of the IgM isotype lymphocyte response in association with intestinal microbial colonisation is in keeping with previous findings that young infants respond to mucosal stimuli with IgM class antibodies. ${ }^{12} 22$ The increased $\operatorname{IgM}$ response to mucosal stimuli is believed to compensate for the relative absence of IgA early in life. ${ }^{10}{ }^{11}$ In addition, in a study on the expression of homing receptors of peripheral ISCs, the IgM-secreting cells were shown to have more homing tendencies towards the mucosae than IgA and IgG isotypes, and an isotype switch from $\operatorname{IgM}$ to IgA was suggested to take place only after homing to gut mucosa. ${ }^{37}$

It has previously been established that assessment of circulating peripheral blood lymphocytes is a sensitive and specific method for measuring humoral immune responses at mucosal surfaces. ${ }^{38} 39$ A large proportion of peripheral IgA-secreting cells produce polymeric IgA with subclass distribution characteristic of external secretions when stimulated with pokeweed mitogen in vitro. ${ }^{40}$ Therefore most peripheral IgA-secreting cells have been suggested to be precursors of IgA plasma cells with the potential to populate mucosal tissues. $^{240}$ Further support for this notion comes from studies on mice showing that $90 \%$ of all ICSs come from the small intestine, Peyer's patches, or mesenteric lymph nodes, and that nearly all the IgA-secreting cells are found in the small intestine. ${ }^{41}{ }^{42}$ The increased number of circulating IgA-secreting and IgMsecreting cells found in this study may thus also reflect improved mucosal protection against antigens met by the intestinal surfaces.

Our results suggest that there is a connection between the method of delivery and maturation of the humoral immune system for the following reasons. A delay in intestinal colonisation with $B$ fragilis is the most permanent difference in neonates delivered by caesarean section compared with vaginally delivered infants. ${ }^{13} 14{ }^{43}$ We recently established that rates of colonisation by $B$ fragilis and Bifidobacterium-like and Lactobacillus-like bacteria were significantly lower during the first few months of life in infants born by caesarean section than in naturally born infants. ${ }^{19}$ The most consistent difference in the colonisation rates between the two groups was seen in that of $B$ fragilis. None of the infants delivered by caesarean section had permanent colonisation with $B$ fragilis before 2 months of age whereas $52-79 \%$ of the vaginally delivered infants were colonised with these bacteria during that period. At 6 months of age, the colonisation rate for $B$ fragilis in the infants delivered by caesarean section was still only half $(36 \%)$ of that in the vaginally delivered infants $(76 \%){ }^{19}$ Thus the important immunostimulating effect of Bacteroides sp is lacking in these infants during a critical period of immunological maturation.

Our observations add an interesting facet to the discussion on the possible protective role of microbial contacts in the prevention of allergic diseases. ${ }^{44-46}$ This protective effect has been explained by the microbes' ability to change the $\mathrm{T}$ helper cell balance from the neonatally predominating $\mathrm{T}$ helper 2 phenotype, which instructs uncommitted B lymphocytes to produce IgE through release of interleukin 4, to the $\mathrm{T}$ helper 1 phenotype during a critical period in infancy before the immunological memory has developed. ${ }^{27}{ }^{47}$ The exact timing of the $\mathrm{T}$ helper cell polarisation is not known, but early infancy is the most logical time. ${ }^{48}$ The factors that divert this process are not known, but animal studies suggest that one could be the indigenous bacterial flora. ${ }^{9}$ Furthermore, we now show that microbes of the normal flora stimulate maturation of IgA-secreting cells, the first line immune protection against foreign antigens at the mucosal membranes. ${ }^{49}$ It may therefore be no coincidence that the incidence of allergic diseases are increasing in parallel with the rate of sterile caesarean sections.

We thank Tuija Poussa, MSc, for statistical help, research nurse Satu Ekblad, for help with the clinical work, Mrs Tuija Turjas and Mrs Etta-Liisa Väänänen, for performing the ELISPOT assays, and Mr Erkki Nieminen, MSc, for help in preparing the figures. This study was supported by the South-West Finnish figures. This study was supported by the South-West Finnish
Fund of Neonatal Research and the Finnish Cultural Foundation. 
1 Gaskins HR. Immunological aspects of host/microbiota interactions at the intestinal epithelium. In: Mackie RI White BA, Isaacson RE, eds. Gastrointestinal microbiology. Volume 2: gastrointestinal microbes and host interactions. New

2 Mestecky J. The common mucosal immune system and current strategies for induction of immune responses in external secretions. F Clin Immunol 1987;7:265-76.

3 MacDonald TT. Development of mucosal immune function in man: potential for GI disease states. Acta Paediatr $7 p n$ 1994;36:532-6.

4 Savilahti E. Immunoglobulin-containing cells in the intestinal mucosa and immunoglobulins in the intestinal juice in children. Clin Exp Immunol 1972;11:415-25.

5 Burgio GR, Lanzavecchia A, Plebani A, Jayakar S, Ugazio AG. Ontogeny of secretory immunity: levels of secretory IgA and natural antibodies in saliva. Pediatr Res 1980;14:1111-14.

6 Rothkötter HJ, Pabst R. Lymphocyte subsets in jejunal and ileal Peyer's patches of normal and gnotobiotic minipigs. Immunology 1989;67:103-8.

7 Crabbé PA, Nash DR, Bazin H, Eyssen H, Heremans JF. Immunohistochemical observations on lymphoid tissues from conventional and germ-free mice. Lab Invest 1970;22:448-57.

8 Bos NA, Meeuwsen CG, Wostmann BS, Pleasants JR, Benner R. The influence of exogenous antigenic stimulation on the specificity repertoire of background immunoglobulin-secreting cells of different isotypes. Cell Immunol 1988;112:371-80.

9 Sudo N, Sawamura S, Tanaka K, Aiba Y, Kubo C, Koga Y. The requirement of intestinal bacterial flora for the development of an IgE production system fully susceptible to oral tolerance induction. F Immunol 1997;159:1739-45.

10 Mellander L, Carlsson B, Hanson LÅ. Appearance of secretory IgM and IgA antibodies to Escherichia coli in saliva during early infancy and childhood. $f$ Pediatr 1984;104:564-8.

11 Mellander L, Carlsson B, Jalil F, Söderström T, Hanson LÅ Secretory IgA antibody response against Escherichia coli
antigens in infants in relation to exposure. $\mathcal{F}$ Pediatr antigens in infants

12 Lodinová-Zádníková $\mathrm{R}$, Slavíková $\mathrm{M}$, Tlaskalová-Hogenová $\mathrm{H}$, et al. The antibody response in breast-fed and non-breast-fed infants after artificial colonization of the intestine with Escherichia coli O83. Pediatr Res 1991;29:396-9.

13 Long SS, Swenson RM. Development of anaerobic fecal flora in healthy newborn infants. F Pediatr 1977;91:298301.

14 Bennet R, Nord CE. Development of the faecal anaerobic microflora after caesarean section and treatment with antibiotics in newborn infants. Infection 1987:15:332-6.

15 Eskew PN, Jr, Saywell RM, Jr, Zollinger TW, Erner BK, Oser TL. Trends in the frequency of cesarean delivery. A 21-year experience

16 Macfarlane A. At last, maternity statistics for England. BMf 1998;316:566-7.

17 Rook GAW, Stanford JA. Give us this day our daily germs. Immunol Today 1998;19:113-16.

18 Lester BM, Boukydis CFZ, Garcia-Coll CT, Hole WT Colic for developmentalists. Infant Mental Health fournal 1990;11:321-33.

19 Grönlund MM, Lehtonen OP, Eerola E, Kero P. Faecal microflora in healthy infants born by different methods of delivery: permanent changes in intestinal flora after caesarean delivery. $f$ Pediatr Gastroenterol Nutr 1999;28:19-25.

20 Czerkinsky CC, Nilsson LÅ, Nygren H, Ouchterlony Ö, Tarkowski A. A solid-phase enzyme-linked immunospot (ELISPOT) assay for enumeration of specific antibodysecreting cells. F Immunol Methods 1983;65:109-21.

21 Sedgwick JD, Holt PG. A solid-phase immunoenzymatic technique for the enumeration of specific antibodysecreting cells. F Immunol Methods 1983;57:301-9.

22 Isolauri E, Virtanen E, Jalonen T, Arvilommi H. Local immune response measured in blood lymphocytes reflects the clinical reactivity of children with cow's milk allergy. the clinical reactivity of child
Pediatr Res $1990 ; 28: 582-6$.

23 Kantele A. Immune response to prolonged intestinal exposure to antigen. Scand $\mathcal{F}$ Immunol 1991;33:225-9.
24 Isolauri E, Sütas Y, Mäkinen-Kiljunen S, Oja SS, Isosomppi R, Turjanmaa K. Efficacy and safety of hydrolyzed cow milk and amino acid-derived formulas in infants with cow milk allergy. F Pediatr 1995;127:550-7.

25 David TJ. Infant feeding causes all cases of asthma, eczema, and hay fever. Or does it? Arch Dis Child 1998;79:97-8.

26 Dannaeus A. Age-related antibody response to food antigens. Pediatric Allergy and Immunology 1993;4(suppl 3): $21-4$.

27 Holt PG. Immunoprophylaxis of atopy: light at the end of the tunnel? Immunol Today 1994;15:484-9.

28 Simon GL, Gorbach SL. Intestinal flora in health and disease. Gastroenterology 1984;86:174-93.

29 Kleessen B, Bunke H, Tovar K, Noack J, Sawatzki G. Influence of two infant formulas and human milk on the development of the faecal flora in newborn infants. Acta Paediatr 1995;84:1347-56.

30 Yoshioka H, Iseki K, Fujita K. Development and differences of intestinal flora in the neonatal period in breast-fed and of intestinal flora in the neonatal period in br

31 Bengmark S. Ecological control of the gastrointestinal tract. The role of probiotic flora. Gut 1998;42:2-7.

32 Elhag KM, Senthilselvan A. A serogrouping scheme for the study of the epidemiology of Bacteroides fragilis. $7 \mathrm{Med}$ Microbiol 1988:27:199-205.

33 Moreau MC, Ducluzeau R, Guy-Grand D, Muller MC. Increase in the population of duodenal immunoglobulin A plasmocytes in axenic mice associated with different living or dead bacterial strains of intestinal origin. Infect Immun 1978;21:532-9.

34 Pulverer G, Ko HL, Roszkowski W, Beuth J, Yassin A, Jeljaszewicz J. Digestive tract microflora liberates low molecular weight peptides with immunotriggering activity. Int $7 \mathrm{Med}$ Microbiol 1990;272:318-27.

35 Dahlgren UI, Wold AE, Hanson LÅ, Midtvedt T. Expression of a dietary protein in E. coli renders it strongly anti.

36 Kramer DR, Cebra JJ. Early appearance of "natural" mucosal IgA responses and germinal centers in suckling mucosal IgA responses and germinal centers in suckling mice developing in the absence

37 Kantele JM, Kantele A, Arvilommi H. Circulating immunoglobulin-secreting cells are heterogeneous in their expression of maturation markers and homing receptors. Clin Exp Immunol 1996;104:525-30.

38 Forrest BD. Identification of an intestinal immune response using peripheral blood lymphocytes. Lancet 1988;1:81-3.

39 Kantele AM, Takanen R, Arvilommi H. Immune response to acute diarrhea seen as circulating antibody-secreting cells. F Infect Dis 1988;158:1011-16.

40 Kutteh WH, Koopman WJ, Conley ME, Egan ML, Mestecky J. Production of predominantly polymeric IgA by human peripheral blood lymphocytes stimulated in vitro with mitogens. F Exp Med 1980;152:1424-9.

41 Van der Heijden PJ, Stok W, Bianchi AT. Contribution of immunoglobulin-secreting cells in the murine small intestine to the total 'background' immunoglobulin production. Immunology 1987;62:551-5.

42 Van der Heijden PJ, Bianchi AT, Stok W, Bokhout BA. Background (spontaneous) immunoglobulin production in the murine small intestine as a function of age. Immunology 1988;65:243-8.

43 Neut C, Bezirtzoglou E, Romond C, Beerens H, Delcroix $\mathrm{M}$, Noel AM. Bacterial colonization of the large intestine in newborns delivered by cesarean section. Zentralbl Bakteriol Mikrobiol Hyg A 1987;266:330-7.

44 Shaheen SO, Aaby P, Hall AJ, et al. Measles and atopy in Guinea-Bissau. Lancet 1996;347:1792-6.

45 Matricardi PM, Rosmini F, Ferrigno L, et al. Cross sectional retrospective study of prevalence of atopy among Italian military students with antibodies against hepatitis A virus. BMF 1997;314:999-1003.

46 Shirakawa T, Enomoto T, Shimazu S, Hopkin JM. The inverse association between tuberculin responses and atopic disorder. Science 1997;275:77-9.

47 Cookson WO, Moffatt MF. Asthma: an epidemic in the absence of infection? Science 1997;275:41-2.

48 Hogg C. T-helper polarization in atopic disease: how early does it occur? Clin Exp Allergy 1997;27:1237-9.

49 Brandtzaeg P. Molecular and cellular aspects of the Brandtzaeg P. Molecular and cellular aspects of the
secretory immunoglobulin system. APMIS 1995;103:119. 